\title{
Resilience and vulnerability: a neurobiological perspective
}

\author{
Ilia N. Karatsoreos ${ }^{1}$ and Bruce S. McEwen ${ }^{2 *}$
}

\author{
Addresses: ${ }^{1}$ Department of Integrative Physiology and Neuroscience, Washington State University, Veterinary and Biomedical \\ Research Building, 1815 Ferdinand's Lane, Pullman, WA, 99163; ${ }^{2}$ Laboratory of Neuroendocrinology, The Rockefeller University, \\ Weiss Research Building, 1230 York Ave, New York, NY, 10065 \\ * Corresponding author: Bruce S. McEwen (mcewen@mail.rockefeller.edu) \\ FI000Prime Reports 2013, 5:13 (doi:10.12703/P5-13) \\ This is an open-access article distributed under the terms of the Creative Commons Attribution-Non Commercial License \\ (http://creativecommons.org/licenses/by-nc/3.0/legalcode), which permits unrestricted use, distribution, and reproduction in any medium, \\ provided the original work is properly cited. You may not use this work for commercial purposes.
}

The electronic version of this article is the complete one and can be found at: http://f $1000 . c o m / p r i m e /$ reports/b/5//3

\begin{abstract}
The brain is constantly adapting to a changing environment. It detects environmental stimuli, integrates that information with internal states, and engages appropriate behavioral and physiological responses. This process of stability through change is termed "allostasis", and serves as a mechanism by which an organism can adapt to a changing environment to function optimally, and ultimately ensure survival. The ability to adapt to stressors in the environment by "bending" but not "breaking" can be considered as "resilience". Individuals that are more able to withstand such challenges to their stability, and bounce back after, can be considered more resilient than those that do not. This review will explore what resilience means in a neurobiological context, the role of stress and allostasis, and focuses on the role of neurotrophins, particularly BDNF, in mediating adaptive plasticity.
\end{abstract}

\section{Introduction}

Over millions of years, evolution has crafted organisms that are exquisitely suited to their environments. Organisms possess characteristics that ensure optimal function in a given environment, but these same qualities may not be beneficial in other environments, and in some cases, could be detrimental to fitness. However, no environment is completely stable, and even the most finely tuned organism must be prepared to adapt to brief changes in the environment in order to ensure survival. This has resulted in the evolution of structures and systems aimed at ensuring adaptation to changing environments, providing organisms with the capacity to cope with environmental challenges, and exhibit resilience to shifts in their normal operating ranges. The goal of this review is to highlight the emerging area of resilience at the level of the nervous system, and it will focus on those systems that allow an organism to exhibit resilience to environmental challenges, as well as what occurs when these systems fail. In addition, we will emphasize that this is a complex brain-body interaction, as oftentimes neuroscientists may ignore the role of the rest of the body, while organismal physiologists may not take into account neural responses that regulate peripheral physiology.

\section{How do we illustrate resilience in biological systems?}

Before attempting to explore neurobiological resilience, it is helpful to consider how resilience may be defined more generally. A simple broad definition of resilience in biological systems can be thought of as those factors that contribute to an organism's ability to cope with environmental challenges, thus ensuring survival. Take the structure of a palm tree. The typical tall palm found in tropical paradises has a very thin, flexible trunk, with a limited number of fronds at the very top, and no other branches along the way. Why is this architecture found in tropical palms, but not in trees resident to deciduous forests in cooler climes? In addition to ample heat and sun, the environment in the tropics is usually quite breezy, and this morphological arrangement allows the tree to gently sway in the wind. When violent hurricanes inflict their damage and destruction in these coastal communities, the morphology of the palms allows many of them to withstand the violent winds, not by rigid resistance of 
the wind, but by a gradual bending. The trees bend, but do not break. In a sense, this can be thought of as the broad definition of resilience - the ability of an organism to cope with environmental tumult by bending, and not breaking. But how do we define this in the context of neurobiology?

An eloquent way of thinking about resilience was put forward by Ann Masten (2012), by suggesting "resilience is the capacity of a dynamic, malleable system to withstand challenges to its stability, viability or development." [1]. As such, vulnerability may be considered the flipside of resilience. Vulnerable individuals may be those in which the systems of resilience do not function adequately, or in which the challenge is, for some reason, experienced in an amplified way.

\section{Resilience and vulnerability: physiological and neural contexts}

Studying the neurobiology of resilience and vulnerability is a difficult task that requires considering myriad systems that are involved in both maintaining homeostasis (those factors necessary for life) as well as systems that mediate "allostasis", or physiological changes that occur in response to environmental perturbations [2-5]. A useful, though sometimes misunderstood, concept to explore these systems is "stress". While Hans Selye initially borrowed the term in the 1930s from the field of engineering, it is an appropriate concept when discussing resilience and vulnerability. Engineering defines stress as a measure of the internal forces acting within a deformable body - an apt definition when considered in the context of the "bend but not break" metaphor of resilience. In Selye's interpretation, stress was the result of an organism's failed attempts to appropriately cope with a physical challenge [6], and since then the definition of stress has expanded to contain ideation or anticipation of impending threats [7]. The concept of stress has had enormous impact both on pop culture as well as modern neuroscience. As Richard Schweder suggested in a 1997 New York Times Op Ed piece, the word "stress" is America's latest export in a stressed-out world, and is "just as useful as a Visa card, and as satisfying as a Coke."

When an organism experiences a perturbation in the environment, allostatic responses are mobilized in order to provide stability through active intervention. In many cases, this mobilization includes the activation of the "stress response". Though "stress" carries with it a negative connotation, it is important to note that the allostatic responses play important roles in ensuring an organism can appropriately adapt to a changing environment, and do not represent purely negative responses (See Table 1; though the concept of "toxic stress" is an important one, it falls outside the scope of this paper). Allostatic responses are inherently brain-body responses, with the brain detecting threats, and then engaging both neural and peripheral responses. The concept of allostasis focuses on mediators that allow adaptation, with cortisol being perhaps one of the best studied, but it also includes metabolic hormones, immune mediators, and autonomic nervous system outflows. A key aspect of allostasis is that these mediators serve in the short term to help promote adaptation, but these same mediators can result in pathophysiologic responses when they are dysregulated or become overused [8]. In keeping with the brain-body theme, a good example of this pathophysiology is the inflammatory response. The sympathetic and parasympathetic nervous systems modulate inflammatory cytokines, with the former stimulating their production, and the latter inhibiting them (reviewed in $[9,10])$. In addition, inflammatory cytokines may stimulate cortisol production, which in turn can lead to inhibition of the inflammatory response. As such, should these complementary systems become unbalanced, e.g. if corticosteroid levels are too high, appropriate inflammatory responses may be inhibited during immune challenge, but on the other hand, if the levels are too low, "normal" immune responses become uncontained, and rampant inflammation out of scale with the initial challenge can result.

But how does the concept of allostasis relate to resilience and vulnerability? Any new experiences result in neural activity that drives adaptive plasticity, and these responses are mediated by systemic hormone, endogenous excitatory amino acids, and neurotrophic factors to name but a few. Changes in how such mediators and processes respond to new experiences could possibly explain differences in resilience and vulnerability, both mental and physical, to environmental and psychological stressors.

Table I. Concepts and definitions of stress

\begin{tabular}{lll}
\hline Positive stress & Tolerable stress & Toxic stress \\
\hline $\begin{array}{l}\text { Exhilaration from a challenge that has } \\
\text { a satisfying outcome }\end{array}$ & $\begin{array}{l}\text { Adverse life events but good social and } \\
\text { emotional support }\end{array}$ & Exacerbated by chaos, abuse and neglect \\
Sense of mastery and control & & Poor social and emotional support \\
Good self esteem & & Unhealthy brain architecture \\
\end{tabular}




\section{Neural mediators of resilience}

While cortisol is an important allostatic mediator, other factors are surely involved. For instance, neurotrophins such as brain derived neurotrophic factor (BDNF) play a key role [11]. It has been demonstrated that chronic stress can decrease BDNF expression in the brain $[12,13]$, though this relationship is a complex one $[14,15]$ with reciprocal cross-talk between glucocorticoids and BDNF signaling. However, recently, a common polymorphism in the BDNF gene has been identified in humans, in which there is substitution of a valine at codon 66 with a methionine (val66met). Individuals who carry this mutation demonstrate reduced performance in hippocampal-dependent memory tasks and increased anxiety. The val66met mouse was developed using a transgenic approach. The mice have decreased BDNF secretion, a reduction in hippocampal volume, and changes in cognition [16,17], as well as increased anxiety levels $[18,19]$. In these models, alterations in BDNF signaling can be considered "risk factors" in the development of neuropsychiatric disease $[20,21]$.

Other studies have suggested an additional interpretation, in which BDNF is a necessary factor in the ability of the brain to show plasticity. For example, BDNF haploinsufficient mice show shrunken dendrites in the CA3 region of the hippocampus. However, these mice do not show further shrinkage of hippocampal dendrites when chronically stressed in contrast to WT mice, which do show stress-induced shrinkage [22]. The mechanisms by which BDNF plays these somewhat contradictory roles could be explained by a necessity for BDNF in plasticity in general, from neurite outgrowth and spine remodeling, to destabilization of existing spines $[23,24]$. Thus, trophic factors such as BDNF are facilitators of plasticity, and the outcome may be negative (e.g. epilepsy [25]) or positive (e.g. recovery from depression [26]) depending on the complex, perhaps hermetic, processes that are operating at the time.

\section{BDNF, depression, windows of plasticity, and resilience}

While there are many potential mediators of resilience, we will focus on the potential role of BDNF in this short review. In some views, depression may be a consequence of inadequate resilience to psychological stressors. Numerous studies suggest that depression is more prevalent in individuals who have had adverse early life experiences [27]. Importantly, low BDNF may be a key feature of the depressive state, and elevation of BDNF by diverse treatments ranging from antidepressant drugs, such as fluoxetine, to regular physical activity may be a key feature of treatment [28]. A growing view is that such treatments may "reopen" windows of plasticity, and effectively provide a means to engage plasticity systems that can help ameliorate depressive moods by altering the neural pathways that underlie them. Such drugs may also increase plasticity more generally, as the recently reported ability of fluoxetine to enhance recovery from stroke suggests [29]. However, a key aspect of this new view [30] is that, while such drugs open these "windows of opportunity", the effects will only be capitalized on by a positive behavioral intervention, e.g. behavioral therapy in the case of depression or on intensive physiotherapy to promote neuroplasticity to counteract the effects of a stroke.

This is consistent with animal models that show that ocular dominance imbalance from early monocular deprivation can be reversed by patterned light exposure in adulthood that can be facilitated by fluoxetine, on the one hand, [31] and food restriction (or, alternatively, intermittent glucocorticoid treatment), on the other hand [32], in which inhibitory neuronal activity plays a key role [33]. Investigations of underlying mechanisms for the reestablishment of a new window of plasticity are focusing on the balance between excitatory and inhibitory transmission and molecules that put the "brakes" on such plasticity [34].

As to the role of glucocorticoids, there is a biphasic relationship to plasticity, as shown by studies in which the turnover of dendritic spines in the cortex is inhibited when hypothalamic pituitary adrenal (HPA) function is suppressed by a small dose of dexamethasone and restored in a biphasic manner by increasing replacement levels of corticosterone [35]. This may be related to the finding that corticoids acutely and ligand-independently activate the trkB receptor [36] and that chronic corticoid treatment has the opposite effect [37].

\section{When good intentions lead to negative outcomes}

Allostatic responses are crucial to allow an organism to adapt to a changing environment and cope with perturbations that, if left unchecked, could lead to decreased fitness, or even death. A key point to emphasize is, as in many domains, timing is everything. The responses of the brain and body to environmental challenges need to be well regulated in the temporal domain: activated quickly and only in the appropriate situations, maintained for the duration of the perturbation, and terminated efficiently and effectively. Similarly, these responses may change depending on the life history stage of the organism, making different responses appropriate at different stages of development [4]. Thus, it should be evident that mediators of allostasis can have beneficial effects on fitness when 
deployed at the appropriate time and in the appropriate manner, but they can have unintended effects when they occur outside these boundaries, thereby interfering with optimal function, and negatively impacting fitness [4]. An interesting exercise is exploring the "Hawk vs Dove" personality types that are seemingly widespread in the animal kingdom, including in humans. Each type can be successful in a range of environmental and social conditions, but not in all. When such a mismatch occurs, the same characteristics that made an individual more resilient in one environment can open them up to a host of vulnerabilities in another [38]. Taken in that context, organisms can show resilience not only in their recovery from stress-induced changes but also by their ability to demonstrate experience-related change [39-41].

\section{Conclusions and future directions}

This review explored the ideas of stress and allostasis in the context of resilience, or the ability of an organism to withstand challenges to stability from environmental or psychological perturbations. We further explored what is meant by resilience and vulnerability in the context of neural function, focusing on BDNF as a key player. The roles of neurotrophins, such as BDNF, are central in our thinking of how the brain promotes adaptation to environmental challenge, as they seem central to the mechanisms that the brain uses to promote adaptive plasticity. Finally, we discussed how these "windows of opportunity" can be reopened by treatments that increase BDNF function, and that to capitalize on these new opportunities, behavioral interventions must also be applied.

This research is an area of great promise, and with appropriate efforts exploring both the phenomenology (e.g. other environmental factors that can promote resilience, or impart vulnerabilities), as well as the neural mechanisms that modulate these effects (e.g. epigenetic modifications, neurotrophin signaling, and morphological changes), perhaps we can unlock the secrets by which the brain helps us to adapt to and cope with a changing environment. Understanding the conditions and mechanisms that promote plasticity in "normal" adaptive situations may help us find ways to intervene when these systems fail, and compromise an individual's resilience.

\section{Abbreviations}

BDNF, brain derived neurotrophic factor; HPA, hypothalamic pituitary adrenal.

\section{Disclosures}

The authors declare that they have no disclosures.

\section{References}

I. Masten AS: Risk and resilience in development. In Handbook of Developmental Psychology. Edited by Zelazo PD. Oxford University Press; In Press.

2. Sterling P, Eyer J: Allostasis: A new paradigm to explain arousal pathology. In Handbook of Life Stress, Cognition and Health. Edited by Fisher S, Reason J. New York: John Wiley \& Sons; 1988:629-49.

3. McEwen BS: Stress, adaptation, and disease. Allostasis and allostatic load. Ann N Y Acad Sci 1998, 840:33-44.

4. McEwen BS, Wingfield JC: The concept of allostasis in biology and biomedicine. Horm Behav 2003, 43:2-I5.

5. McEwen BS, Stellar E: Stress and the individual. Mechanisms leading to disease. Arch Intern Med 1993, I53:2093-I0I.

6. Selye $\mathrm{H}$ : A syndrome produced by diverse nocuous agents. 1936. J Neuropsychiatry Clin Neurosci 1998, 10:230-I.

FlOOOPrime
RECOMMENDED

7. Schulkin J, McEwen BS, Gold PW: Allostasis, amygdala, and anticipatory angst. Neurosci Biobehav Rev 1994, 18:385-96.

8. McEwen BS: Protective and damaging effects of stress mediators: central role of the brain. Dialogues Clin Neurosci 2006, 8:367-8I.

9. Sapolsky RM, Romero LM, Munck AU: How do glucocorticoids influence stress responses? Integrating permissive, suppressive, stimulatory, and preparative actions. Endocr Rev 2000, 2I:55-89.

10. Sorrells SF, Sapolsky RM: An inflammatory review of glucocorticoid actions in the CNS. Brain Behav Immun 2007, 21 :259-72.

\section{FlOOOPrime} RECOMMENDED

II. Chen Z, Bath K, McEwen B, Hempstead B, Lee F: Impact of genetic variant BDNF (Val66Met) on brain structure and function. Novartis Found Symp 2008, 289:180-8; discussion 188-95.

12. Smith MA, Cizza G: Stress-induced changes in brain-derived neurotrophic factor expression are attenuated in aged Fischer 344/N rats. Neurobiol Aging 1996, 17:859-64.

FlOOOPrime RECOMMENDED

13. Smith MA, Makino S, Kvetnanský R, Post RM: Effects of stress on neurotrophic factor expression in the rat brain. Ann $N$ Y Acad Sci 1995, 771:234-9.

FlOOOPrime

14. Isgor C, Kabbaj M, Akil H, Watson SJ: Delayed effects of chronic variable stress during peripubertal-juvenile period on hippocampal morphology and on cognitive and stress axis functions in rats. Hippocampus 2004, 14:636-48.

\section{FlOOOPrime} RECOMMENDED

I5. Kuroda Y, McEwen BS: Effect of chronic restraint stress and tianeptine on growth factors, growth-associated protein-43 and microtubule-associated protein 2 mRNA expression in the rat hippocampus. Brain Res Mol Brain Res 1998, 59:35-9.

16. Egan MF, Kojima M, Callicott JH, Goldberg TE, Kolachana BS, Bertolino A, Zaitsev E, Gold B, Goldman D, Dean M, Lu B, Weinberger DR: The BDNF val66met polymorphism affects activity-dependent secretion of BDNF and human memory and hippocampal function. Cell 2003, I I2:257-69.

\section{FlOOOPrime} RECOMMENDED

17. Hariri AR, Goldberg TE, Mattay VS, Kolachana BS, Callicott JH, Egan MF, Weinberger DR: Brain-derived neurotrophic factor val66met polymorphism affects human memory-related 
hippocampal activity and predicts memory performance. J Neurosci 2003, 23:6690-4.

\section{FlOOOPrime}

18. Jiang $X, X u$ K, Hoberman J, Tian F, Marko AJ, Waheed JF, Harris CR, Marini AM, Enoch M, Lipsky RH: BDNF variation and mood disorders: a novel functional promoter polymorphism and Val66Met are associated with anxiety but have opposing effects. Neuropsychopharmacology 2005, 30:1353-61.

\section{FlOOOPrime}

19. Lang UE, Hellweg R, Kalus P, Bajbouj M, Lenzen KP, Sander T, Kunz D, Gallinat J: Association of a functional BDNF polymorphism and anxiety-related personality traits. Psychopharmacology (Berl) 2005, 180:95-9.

\section{FlOOOPrime}

\section{RECOMMENDED}

20. Bath KG, Lee FS: Variant BDNF (Val66Met) impact on brain structure and function. Cogn Affect Behav Neurosci 2006, 6:79-85.

\section{FlOOOPrime}

21. Soliman F, Glatt CE, Bath KG, Levita L, Jones RM, Pattwell SS, Jing D, Tottenham N, Amso D, Somerville LH, Voss HU, Glover G, Ballon DJ, Liston C, Teslovich T, van Kempen T, Lee FS, Casey BJ: A genetic variant BDNF polymorphism alters extinction learning in both mouse and human. Science 2010, 327:863-6.

\section{FlOOOPrime}

\section{RECOMMENDED}

22. Magariños AM, Li CJ, Gal Toth J, Bath KG, Jing D, Lee FS, McEwen BS: Effect of brain-derived neurotrophic factor haploinsufficiency on stress-induced remodeling of hippocampal neurons. Hippocampus 201I, 21:253-64.

23. Horch HW, Katz LC: BDNF release from single cells elicits local dendritic growth in nearby neurons. Nat Neurosci 2002, 5: I I77-84.

FlOOOPrime RECOMMENDED

24. Horch HW, Krüttgen A, Portbury SD, Katz LC: Destabilization of cortical dendrites and spines by BDNF. Neuron 1999, 23:353-64.

\section{FlOOOPrime}

\section{RECOMMENDED}

25. Heinrich C, Lähteinen S, Suzuki F, Anne-Marie L, Huber S, Häussler U, Haas C, Larmet $Y$, Castren E, Depaulis A: Increase in BDNFmediated TrkB signaling promotes epileptogenesis in a mouse model of mesial temporal lobe epilepsy. Neurobiol Dis 2011, 42:35-47.

26. Castrén E: Is mood chemistry? Nat Rev Neurosci 2005, 6:24I-6.

27. Anda RF, Butchart A, Felitti VJ, Brown DW: Building a framework for global surveillance of the public health implications of adverse childhood experiences. Am J Prev Med 2010, 39:93-8.

28. Duman RS, Monteggia LM: A neurotrophic model for stressrelated mood disorders. Biol Psychiatry 2006, 59: I | |6-27.

\section{FlOOOPrime \\ RECOMMENDED}

29. Chollet F, Tardy J, Albucher J, Thalamas C, Berard E, Lamy C, Bejot Y, Deltour S, Jaillard A, Niclot P, Guillon B, Moulin T, Marque P,
Pariente J, Arnaud C, Loubinoux I: Fluoxetine for motor recovery after acute ischaemic stroke (FLAME): a randomised placebo-controlled trial. Lancet Neurol 20II, 10:123-30.

\section{FlOOOPrime}

\section{RECOMMENDED}

30. Castrén E, Rantamäki T: The role of BDNF and its receptors in depression and antidepressant drug action: Reactivation of developmental plasticity. Dev Neurobiol 2010, 70:289-97.

\section{FlOOOPrime}

\section{RECOMMENDED}

31. Maya Vetencourt JF, Sale A, Viegi A, Baroncelli L, de Pasquale R, O'Leary OF, Castrén $E$, Maffei $L$ : The antidepressant fluoxetine restores plasticity in the adult visual cortex. Science 2008, 320:385-8.

\section{FlOOOPrime}

32. Spolidoro M, Baroncelli L, Putignano E, Maya-Vetencourt JF, Viegi A, Maffei L: Food restriction enhances visual cortex plasticity in adulthood. Nat Commun 20II, 2:320.

33. Southwell DG, Froemke RC, Alvarez-Buylla A, Stryker MP, Gandhi SP: Cortical plasticity induced by inhibitory neuron transplantation. Science 2010, 327: I|45-8.

\section{FlOOOPrime
RECOMMENDED}

34. Bavelier D, Levi DM, Li RW, Dan Y, Hensch TK: Removing brakes on adult brain plasticity: from molecular to behavioral interventions. J Neurosci 2010, 30: |4964-7|.

35. Liston C, Gan W: Glucocorticoids are critical regulators of dendritic spine development and plasticity in vivo. Proc Nat Acad Sci USA 20II, 108:16074-9.

\section{FlOOOPrime}

36. Jeanneteau F, Garabedian MJ, Chao MV: Activation of Trk neurotrophin receptors by glucocorticoids provides a neuroprotective effect. Proc Natl Acad Sci USA 2008, 105:4862-7.

\section{FIOOOPrime}

37. Numakawa $\mathrm{T}$, Kumamaru E, Adachi N, Yagasaki Y, Izumi A, Kunugi $\mathrm{H}$ : Glucocorticoid receptor interaction with TrkB promotes BDNF-triggered PLC-gamma signaling for glutamate release via a glutamate transporter. Proc Natl Acad Sci USA 2009, 106:647-52.

\section{FlOOOPrime \\ RECOMMENDED}

38. Korte SM, Koolhaas JM, Wingfield JC, McEwen BS: The Darwinian concept of stress: benefits of allostasis and costs of allostatic load and the trade-offs in health and disease. Neurosci Biobehav Rev 2005, 29:3-38.

39. Del Giudice M, Ellis BJ, Shirtcliff EA: The Adaptive Calibration Model of stress responsivity. Neurosci Biobehav Rev 20I I, 35:1562-92.

40. McEwen BS: Brain on stress: how the social environment gets under the skin. Proc Natl Acad Sci USA 2012, I09(Suppl 2):17180-5.

4I. Karatsoreos IN, McEwen BS: Psychobiological allostasis: resistance, resilience and vulnerability. Trends Cogn Sci (Regul Ed) 2011, 1 5:576-84 